\title{
Demographic Profile of the Diabetes mellitus Subjects in Lalitpur and Jhansi Districts of Uttar Pradesh, India
}

\author{
Manju Yadav ${ }^{1}$, K. Uma Maheswari ${ }^{1}$, W. Jessie Suneetha ${ }^{{ }^{*}}$, \\ R. Geetha Reddy ${ }^{2}$ and D. Srinivasa Chary ${ }^{3}$
}

${ }^{1}$ Department of Foods and Nutrition, College of Home Science, PJTS Agricultural University, Rajendranagar, Hyderabad - 500 030, India

${ }^{2}$ Department of Home Science Extension and Communication Management, College of Home Science, PJTSAU, Saifabad, Hyderabad 500 004, India

${ }^{3}$ Department of Mathematics and Statistics, College of Agriculture, PJTSAU, Rajendranagar, Hyderabad - 500 030, India

*Corresponding author

\section{A B S T R A C T}

Diabetes mellitus is one of the most prevalent chronic diseases in the world and the incidence of diabetes has increased dramatically in developing

Keywords

Diabetes mellitus, HRQOL and selfmanagement

Article Info

Accepted:

10 June 2019

Available Online:

10 July 2019 countries such as India. Health-related quality of life (HRQOL) is an important factor for self-management behaviors of diabetic patients. These behaviors have special importance in preventing complications of diabetes. Health-related quality of life (HRQOL) has become an important measure for evaluating patient treatment with non-curable chronic disease. In the present paper demographic profile of 300 diabetes subjects has been presented including 150 males and 150 females from two district of Uttar Pradesh. The demographic profile of respondents depicted age, gender, religion, educational status, life style, marital status, mode of diagnosis of diabetes, monthly income, occupation, hours of work, hours of exercise, smoking and alcohol consumption of respondents. These are the important contributing factors to access the quality of life of diabetic subjects.

\section{Introduction}

Diabetes is a serious chronic disease that occurs either when the pancreas does not produce enough insulin or when the body cannot effectively use the insulin it produces. Diabetes is one of the largest global health emergencies of the 21 st century and is associated with changes in lifestyle resulting in less physical activity and increased obesity. The age-adjusted death rate of diabetes mellitus (DM) is 22.62 per 100000 of the population and it ranks $98^{\text {th }}$ in the world. It can gradually develop complications and is 
known to be associated with an increased cardiovascular risk. It can reduce quality of life and life expectancy (Gebremedhin et al., 2019).

\section{Materials and Methods}

Purposive sampling technique was used to select type 2 diabetic patients (based on inclusion and exclusion criteria confirmed by WHO) from hospitals/clinics or work places. In the present study 300 (150 male and 150 female) with type 2 diabetic subjects were selected from Jhansi and Lalitpur districts of Uttar Pradesh.

A standard questionnaire on QoL instrument for Indian diabetes patients and factors affecting it are social life and work (Nagpal et $a l ., 2010)$ was used for the data collection.

\section{Results and Discussion}

Demographic profile of respondents $(\mathrm{N}=300)$

The results on demographic profile of the selected subjects with type 2 diabetes mellitus depicted in Table 1.

\section{Age}

The results showed that majority of the males and females from both districts were under the age group of 45- 55 years, in Jhansi [males $54.7 \%(n=42)$ and Female $n=54(74.0 \%)]$ and in Lalitpur [male $n=53(70.7 \%)$ Female $n=27$ (36.0\%)].In Jhansi 33.3\% males $(n=25)$ and $21.92 \%$ females $(n=16)$ were in the age group of 55-65 years. Where as in Lalitpur 27.3\% males $(n=28)$ and $25.3 \%$ females $(n=19)$; in Jhansi $2.7 \%$ males $(n=2), 2.7 \%$ females $(n=$ 2) and none of the male subjects and $5.3 \%$ females $(n=4)$ were under age group of $65-75$ years. Whereas under age $>75$ years $9.3 \%$ males $(n=7), 4.1 \%$ females $(n=3)$ in Jhansi; $(21.3 \%)$ males $(n=16)$ and $4.1 \%$ females $(n=$
3) were in Lalitpur.

Singh et al., (2017) conducted a study in Uttar Pradesh to determine the prevalence of diabetes mellitus in rural community by health camp and door to door approach and reported that prevalence of type 2 diabetes in the rural population was found to be $8.03 \%$. Prevalence was higher in female population $(9.91 \%)$ as compared to males (6.79\%). $19.74 \%$ of participants over $70 \mathrm{yrs}$ of age were diabetics while diabetes was present only in $2.95 \%$ of participants in the age group of 25-39 year. The maximum number of diabetes was in the age group of 50-59 years.

Anjana et al., (2011) revealed that age, sex, obesity, hypertension, and family history of diabetes were independent risk factors for diabetes in both urban and rural areas.

\section{Religion}

In Jhansi $93.3 \%$ males $(\mathrm{n}=70)$ and $87.7 \%$ females $(\mathrm{n}=64)$ were Hindus, $4 \%$ males $(\mathrm{n}=$ $3)$ and $12.2 \%$ females $(n=9)$ were Muslims. Among the selected subjects in Jahnsi no one belonged to Christian community, whereas, $2.7 \%$ of both males $(n=2)$ and females $(n=2)$ belonged to other categories. Whereas, results on the religion of the respondents from Lalitpur $98.7 \%$ males $(n=74)$ and $86.7 \%$ females $(\mathrm{n}=65)$ were Hindu; $1.3 \%$ males $(\mathrm{n}=$ 1) and $13.3 \%$ females $(n=10)$ were Muslim. None from Christian community.

\section{Education}

Results with regard to educational qualification among the respondents from Jhansi district showed that $26.7 \%$ males $(\mathrm{n}=$ $20)$ and $4.1 \%$ females $(\mathrm{n}=3)$ were post graduates; $10.7 \%$ males $(n=8)$ and $9.6 \%$ females $(\mathrm{n}=7)$ were under graduates, followed by high school $25.3 \%$ males $(n=19)$ and $17.8 \%$ females $(\mathrm{n}=13)$. At upper primary level both males and females were $8.0 \%(n=6)$ and $13.3 \%$ males $(n=10)$ and $17.8 \%$ females 
$(\mathrm{n}=13)$ were at primary level, while $16.0 \%$ males $(n=12)$ and $45.2 \%$ females $(n=33)$ were illiterates.

Where as in Lalitpur district $33.3 \%$ males $(\mathrm{n}=$ $25)$ and $6.7 \%$ females $(n=6)$ were post graduates; $2.7 \%$ males $(n=2)$ and $13.3 \%$ females $(\mathrm{n}=10)$ were under graduates. Followed by high school $29.3 \%$ males $(\mathrm{n}=$ 22 ) and $18.7 \%$ females $(n=14)$. Educational qualification at upper primary level $30.7 \%$ males $(n=23)$ and $2.7 \%$ females $(n=2) ; 4.0 \%$ males $(n=3)$ and $12.0 \%$ females $(n=12)$ were had primary level education, while $16.0 \%$ males $(n=12)$ and $45.2 \%$ females $(n=$ 33) were uneducated (Fig. 1).

Kapur (2001) detailed that education appeared to affect prognosis in diabetes, by improved understanding and preventive measures, or as a reflection of better economic status.

It also indicates that diagnosis can be delayed by 3-7 years in the less and uneducated sections of the population. Patients with a higher educational status were diagnosed at a younger age, $43.6 \pm 10.7$ years in collegeeducated patients compared with $45.4 \pm 13.1$ years in patients with school education and $50.4 \pm 13.2$ years in illiterate patients.

\section{Lifestyle}

Results on type of lifestyle showed that majority of the subjects were involved in sedentary work $53.3 \%$ males $(n=40)$ and $76.7 \%$ females $(n=56)$ from Jhansi; $82.7 \%$ males $(n=62)$ and $86.7 \%$ females $(n=65)$ from were from Lalitpur. Followed by subjects involved in moderate work among $16 \%$ males $(n=12)$ and $8.0 \%$ females $(n=6)$ were from Jhansi and subjects involved in heavy work $30.7 \%$ males $(n=23)$ and $15.5 \%$ females $(n=11)$ were from Jhansi and $4 \%$ males $(n=3)$ and $10.7 \%$ females $(n=8)$ were from Lalitpur.

\section{Mode of diagnosis}

The results on mode of diagnosis indicated that among males $58.7 \%$ from Lalitpur which was slightly higher than Jhansi $44 \%$ were diagnosed with diabetes through incidental mode whereas among females from Lalitpur had higher percentage $(40 \%)$ of subjects were diagnosed by incidental mode when compared to Jhansi $35.6 \%$. Diagnosis from symptomatic mode among males was higher among subjects from Lalitpur 40\% than Jhansi 38.7\% in Jhansi. Among females 52.1\% from Jhansi and $44 \%$ from Lalitpur were diagnosed through symptomatic mode. Diagnosis at screening mode was lowest when compare to other two modes i.e. incidental and symptomatic. Diagnosis at screening mode among the subjects was $17.3 \%$ males, $12.3 \%$ females from Jhansi and $1.3 \%$ male and $16 \%$ female from Lalitpur.

\section{Monthly income}

Result on monthly income status of the subjects showed that in Jhansi $42.7 \%$ males $(n=32)$ and $37 \%$ females $(n=27)$ family earning was below 10,000 per month; $18.7 \%$ males $(n=14)$ and $12.3 \%$ females $(n=9)$ family earning was between 11,000 to 19,000 per month; $13.3 \%$ males $(n=10)$ and $16.4 \%$ females $(n=12)$ family earning was between 20,000 to 29000 per month and $25.2 \%$ males $(n=19)$ and $34.2 \%$ females $(n=25)$ belongs family earning was above 30,000 per month.

Whereas, from Lalitpur $17.3 \%$ males $(n=13)$ and $44 \%$ females $(n=33)$ family earning was below 10,000 per month; $12 \%$ males $(n=9)$ and $10.7 \%$ females $(n=8)$ family earning was between 11,000 to 19,000 per month; $14.7 \%$ males $(n=11)$ and $8 \%$ females $(n=6)$ family earning was between 20,000 to 29000 per month and $54.7 \%$ males $(n=41)$ and $36 \%$ females $(n=27)$ family earning was group above 30,000 per month. 
Table.1 Demographic profile of the respondents

\begin{tabular}{|c|c|c|c|c|}
\hline \multirow[t]{3}{*}{ Parameters considered } & \multicolumn{4}{|c|}{ Districts } \\
\hline & \multirow{2}{*}{\multicolumn{2}{|c|}{$\begin{array}{c}\text { Jhansi } \\
\text { Number (\%) }\end{array}$}} & \multirow{2}{*}{\multicolumn{2}{|c|}{$\begin{array}{c}\text { Lalitpur } \\
\text { Number }(\%)\end{array}$}} \\
\hline & & & & \\
\hline Age & Male & Female & Male & Female \\
\hline $45-55$ & $41(54.7)$ & $54(74.0)$ & $27(36.0)$ & $53(70.7)$ \\
\hline $55-65$ & $25(33.3)$ & $16(21.96)$ & $28(27.3)$ & $19(25.3)$ \\
\hline $65-75$ & $2(2.7)$ & $2(2.7)$ & $4(5.3)$ & - \\
\hline$>75$ & $7(9.3)$ & $3(4.1)$ & $16(21.3)$ & $3(4)$ \\
\hline Gender & $75(50)$ & $75(50)$ & $75(50)$ & $75(50)$ \\
\hline \multicolumn{5}{|l|}{ Religion } \\
\hline Hindu & $72(96.3)$ & $65(86.6)$ & $74(98.7)$ & $65(86.7)$ \\
\hline Muslim & $3(4.0)$ & $9(12.3)$ & $1(1.3)$ & $10(13.3)$ \\
\hline Christian & - & - & - & - \\
\hline Others & - & - & - & - \\
\hline \multicolumn{5}{|l|}{ Education } \\
\hline PG Education & $20(26.7)$ & $3(4.1)$ & $25(33.3)$ & $5(6.7)$ \\
\hline UG Education & $8(10.7)$ & $7(9.6)$ & $2(2.7)$ & $10(13.3)$ \\
\hline High School & $19(25.3)$ & $13(17.8)$ & $22(29.3)$ & $14(18.7)$ \\
\hline Upper Primary Education & $6(8.06)$ & $4(5.5)$ & $23(30.7)$ & $2(2.7)$ \\
\hline Primary Education & $10(13.3)$ & $13(17.8)$ & $3(4)$ & $9(12)$ \\
\hline No Education & $12(16.0)$ & $33(45.2)$ & 0.0 & $35(46.7)$ \\
\hline \multicolumn{5}{|l|}{ Occupation } \\
\hline Sedentary & $40(53.3)$ & $56(76.7)$ & $62(82.7)$ & $65(86.7)$ \\
\hline Moderate & $12(16.0)$ & $6(8.2)$ & $10(13.3)$ & $2(2.7)$ \\
\hline Heavy & $23(30.7)$ & $11(15.1)$ & $3(4)$ & $8(10.7)$ \\
\hline \multicolumn{5}{|l|}{ Marital status } \\
\hline Married & $71(94.7)$ & $62(84.9)$ & $70(93.3)$ & $57(76)$ \\
\hline Unmarried & $3(4.0)$ & $8(11.0)$ & $4(5.3)$ & $17(22.7)$ \\
\hline Widowed & $1(1.3)$ & $2(2.7)$ & $1(1.3)$ & $1(1.3)$ \\
\hline Divorced & - & $1(1.4)$ & - & - \\
\hline Alone & - & - & - & - \\
\hline \multicolumn{5}{|l|}{ Mode of diagnosis } \\
\hline Incidental & $33(44.0)$ & $26(35.6)$ & $44(58.7)$ & $30(40)$ \\
\hline Symptomatic & $29(38.7)$ & $38(52.1)$ & $30(40)$ & $33(44)$ \\
\hline At Screening & $13(17.3)$ & $9(12.3)$ & $1(1.3)$ & 12(16) \\
\hline \multicolumn{5}{|l|}{ Monthly income } \\
\hline$<10,000$ & $32(42.7)$ & $27(37.0)$ & $13(17.3)$ & $33(44)$ \\
\hline $11,000-19,000$ & $14(18.7)$ & $09(12.3)$ & $9(12)$ & $8(10.7)$ \\
\hline $20,000-29,000$ & $10(13.3)$ & $12(16.4)$ & 11(14.7) & $6(8)$ \\
\hline$>30,000$ & $19(25.3)$ & $25(34.2)$ & $41(54.7)$ & $27(36)$ \\
\hline \multicolumn{5}{|l|}{ Occupation } \\
\hline Government service & $07(9.3)$ & $13(17.8)$ & $27(36)$ & $7(9.3)$ \\
\hline Professional & $05(6.7)$ & $02(2.7)$ & $2(2.7)$ & $5(6.7)$ \\
\hline Private Service & $35(46.7)$ & $08(11.0)$ & $8(10.7)$ & $5(6.7)$ \\
\hline Business & $08(10.7)$ & $04(5.5)$ & $17(22.7)$ & $6(8)$ \\
\hline
\end{tabular}




\begin{tabular}{|l|c|c|c|c|}
\hline $\begin{array}{l}\text { Household Work/Retired } \\
\text { Hours of work }\end{array}$ & $20(26.7)$ & $46(63.0)$ & $21(28)$ & $52(69.3)$ \\
\hline $6-7$ & $43(57.3)$ & $55(75.3)$ & $37(49)$ & $51(68)$ \\
\hline $7-8$ & $09(12.0)$ & $12(16.4)$ & $11(14.7)$ & $11(14.7)$ \\
\hline $8-9$ & $10(13.3)$ & $1(1.4)$ & $11(14.7)$ & $2(2.7)$ \\
\hline $9-10$ & $13(17.3)$ & $03(4.1)$ & $14(18.7)$ & $7(9.3)$ \\
\hline NA & & $2(2.7)$ & $4(5.3)$ \\
\hline Hours of exercise & & & \\
\hline $1 \mathrm{hr}$ & $13(17.3)$ & $15(20.5)$ & $16(21)$ & $15(20)$ \\
\hline $1 / 2 \mathrm{hr}$ & $12(16.0)$ & $25(34.2)$ & $15(20)$ & $27(36)$ \\
\hline $2 \mathrm{hr}$ & $5(6.7)$ & $2(2.7)$ & $11(14)$ & $3(4)$ \\
\hline $11 / 2 \mathrm{hr}$ & $2(2.7)$ & - & $3(4)$ & $3(4)$ \\
\hline NA & $43(57.3)$ & $31(42.5)$ & $30(40)$ & $27(36)$ \\
\hline Smoking & & & $4(5.3)$ \\
\hline Yes & $15(20.0)$ & $2(2.7)$ & $12(16)$ & $71(94.7)$ \\
\hline No & $60(80.0)$ & $71(97.3)$ & $63(84)$ & $2(2.7)$ \\
\hline Alcohol consumption & & & & $73(97.3)$ \\
\hline Yes & $11(14.7)$ & $01(1.4)$ & $7(9.3)$ & \\
\hline No & $64(85.3)$ & $72(98.6)$ & $68(90.7)$ & \\
\hline
\end{tabular}

Note: J= Jhansi and L= Lalitpur

Sample size $=300, \mathrm{~J}=150(\mathrm{M}=75$ and $\mathrm{F}=75)$ and $\mathrm{L}=150(\mathrm{M}=75$ and $\mathrm{F}=75)$

Values in parenthesis are expressed as percentage

Fig.1 Educational qualification of selected subjects for study from both districts

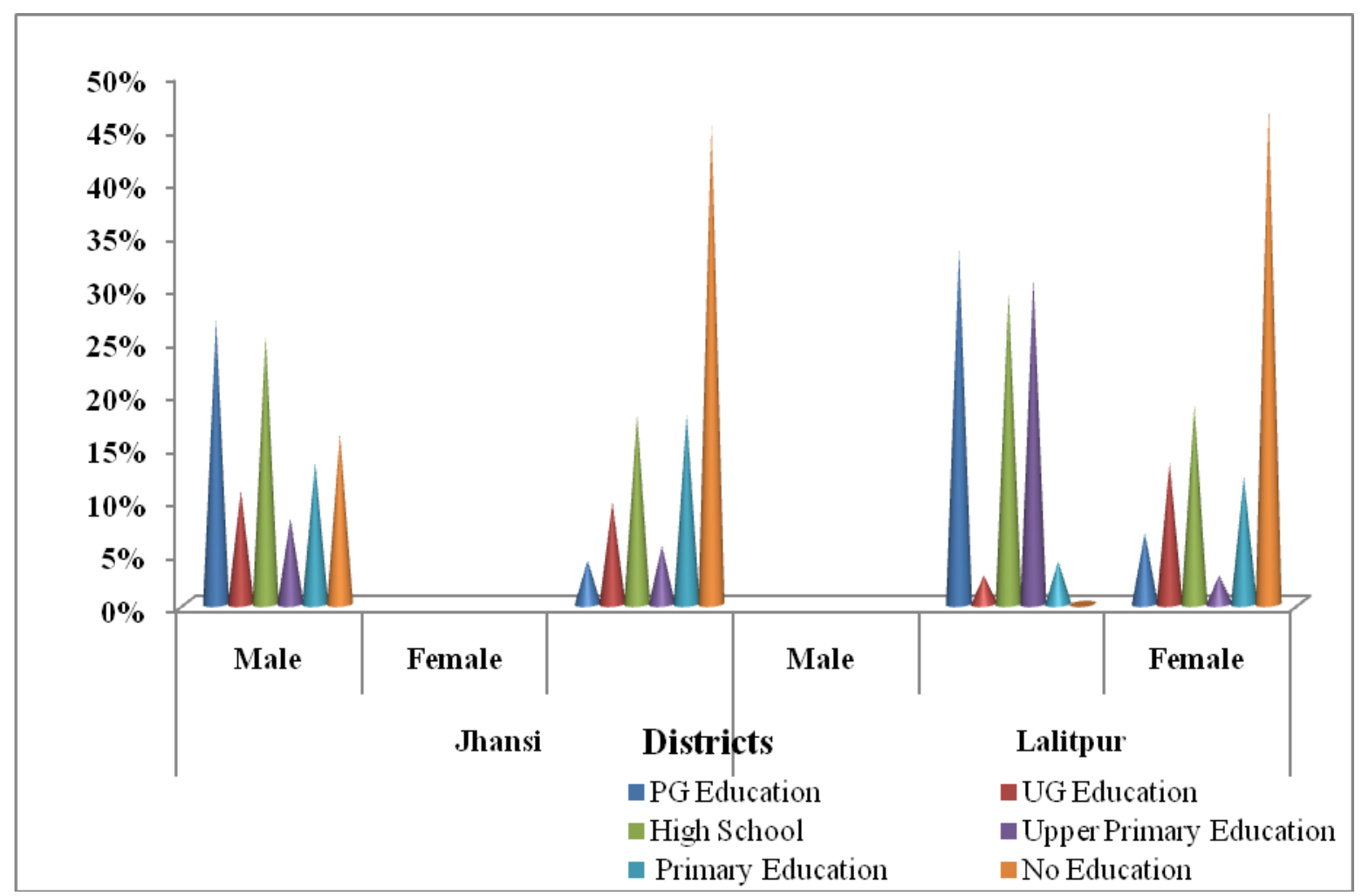




\section{Occupation}

Results on occupation showed that, 9.3\% males $(n=7)$ and $17.8 \%$ females $n=13$ were in government services; $6.7 \%$ males $(\mathrm{n}=5)$ and $2.7 \%$ females $(\mathrm{n}=2)$ were in professional work; $46.7 \%$ males $(\mathrm{n}=35)$ and $11 \%$ females $(\mathrm{n}=8)$ were in private service $10.7 \%$ males $(\mathrm{n}=8)$ and $5.5 \%$ females $\mathrm{n}=4$ were in business and $26.7 \%$ males $(\mathrm{n}=20)$ and $63 \%$ females $(n=63)$ were in Household work/ Retired, among the respondents from Jhansi district.

Whereas from Lalitpur $36 \%$ males $(\mathrm{n}=27)$ and $9.3 \%$ females $(\mathrm{n}=7)$ were in government services; $2.7 \%$ males $(\mathrm{n}=2)$ and $6.7 \%$ females $(\mathrm{n}=5)$ were in professional work; $10.7 \%$ males $(n=8)$ and $6.7 \%$ females $n=5$ were in private service; $22.7 \%$ males $(\mathrm{n}=17)$ and $6 \%$ females $(\mathrm{n}=8)$ were in business and $28 \%$ males $(n=28)$ and $69.3 \%$ females $(n=52)$ were in Household work/ retired.

\section{Hours of work}

Results on hours of work depicted that majority of subjects selected for study were working for 6-7 hours per day (57\% males, $75.3 \%$ females from Jhansi and $49 \%$ males, $68 \%$ females from Lalitpur); $12 \%$ males, $16.4 \%$ females from Jhansi and $14.7 \%$ males and $14.7 \%$ from Lalitpur were working for 7 8 hours per day; $13.3 \%$ males, $4.1 \%$ females from Jhansi and $14.7 \%$ males, $2.7 \%$ females form Lalitpur were working for 8to 9 hours per day where as $17.3 \%$ males, $4.1 \%$ females from Jhansi and $18.7 \%$ males, $9.3 \%$ females from Lalitpur were working for 9 to 10 hours per day.

\section{Hours of exercise per day}

Among males 16\% from Jhansi, 20\% from Lalitpur were doing regular exercise for $1 / 2$ hours per day; $17.3 \%$ from Jhansi, $21 \%$ from
Lalitpur males were doing regular exercise for 1 hours; $2.7 \%$ form Jhansi, 4\% from Lalitpur were doing regular exercise for $1 \frac{1 / 2}{2}$ hours and $6.7 \%$ from Jhansi and 14\% from Lalitpur males were doing exercise 2 hours per day.

Among females $34.2 \%$ from Jhansi, 36\% from Lalitpur were doing regular exercise for $1 / 2$ hours; $20.5 \%$ from Jhansi, $20 \%$ from Lalitpur were doing exercise for 1 hours; none from Jhansi, 4\% from Lalitpur were dong regular exercise for $1 \frac{1 / 2}{2}$ hours where as $2.7 \%$ form Jhansi and $4 \%$ from Lalitpur females were doing regular exercise per for 2 hours.

\section{Smoking and alcohol consumption}

Results showed that smoking 20\% males and $2.7 \%$ females from Jhansi were smokers whereas, $80 \%$ males and $97.3 \%$ females were non-smokers.

In Lalitpur $5.3 \%$ females and $16 \%$ males were smokers while $84 \%$ males and $94.7 \%$ females were nonsmokers.

It was reported that in Jhansi $14.7 \%$ males and $1.4 \%$ females were consuming alcohol whereas; in Lalitpur 9.3\% males and 2.7\% had habit alcohol consumption.

The present study will be helpful to access how age, gender, educational status, monthly income, occupation, hours of work, hours of exercise etc. affecting the health-related quality of life (HRQOL) also to identify important predictors for type 2 Diabetes mellitus.

\section{Acknowledgement}

The authors thank honorable Vice Chancellor of professor Jayashankar Telangana State Agricultural University, Rajendranagar, Hyderabad for his encouragement to carry out this research work. 


\section{References}

Anjana, R.M., Ali, M.K., Pradeepa, R., Deepa, M., Datta, M., Unnikrishnan, R., Rema, M., and Mohan, V. 2011. The need for obtaining accurate nationwide estimates of diabetes prevalence in India - Rationale for a national study on diabetes. Indian Journal of Medical Research. (133):369-80.

Gebremedhin, T., Workicho, A. A. and Angaw, D.A. 2019. Health-related quality of life and its associated factors among adult patients with type II diabetes attending Mizan Tepi University Teaching Hospital, Southwest Ethiopia.BMJ Open Diab Res Care.7 (e000577): 1-8.

Kapur, A. 2001. Influence of socio-economic factors on diabetes care. International Journal of Diabetes of developed countries. (21).

Nagpal J, Kumar A, Kakar S and Bhartiya A. The development of quality of life instrument for Indian diabetes patients (QOLID). A Validation and Reliability Study in Middle and Higher Income Groups 2010; (58): 295-304.

\section{How to cite this article:}

Manju Yadav, K. Uma Maheswari, W. Jessie Suneetha, R. Geetha Reddy and Srinivasa Chary, D. 2019. Demographic Profile of the Diabetes mellitus Subjects in Lalitpur and Jhansi Districts of Uttar Pradesh. Int.J.Curr.Microbiol.App.Sci. 8(07): 903-909. doi: https://doi.org/10.20546/ijcmas.2019.807.108 